\title{
GROOVE DESIGN FOR FORM FIT JOINTS MADE BY ELECTROMAGNETIC PULSE CRIMPING
}

\author{
P. Vanhulsel ${ }^{1}$, M. Van Wonterghem ${ }^{1}$, W. De Waele ${ }^{2}$ and K. Faes ${ }^{3}$ \\ ${ }^{1}$ Ghent University, Belgium \\ ${ }^{2}$ Ghent University, Laboratory Soete, Belgium \\ ${ }^{3}$ Belgian Welding Institute, Belgium
}

\begin{abstract}
The electromagnetic pulse process can be an alternative for many conventional production processes. It can be used for perforating, cutting, welding, forming and crimping. In this thesis, the latter will be investigated in detail, with the emphasis on tubular joints bearing axial tension and/or torsion loading. To get acquainted with the subject, first a literature study was performed concerning the general principles of electromagnetic pulse crimping. Because a new field shaper had to be designed, literature on this topic was also consulted. Finally, the design and use of grooves in crimp joints was studied. It has been reported that an inner piece (mandrel) with additional grooves in the joining zone significantly increases the strength of a crimped joint [1]. However, the information on electromagnetic pulse crimping with a mandrel with more than one groove is very limited. Therefore one of the main goals of this thesis is to determine an optimal design for a mandrel with two grooves used for axially loaded joints. A combination of finite element simulations and experiments was used to draw preliminary conclusions involving the double groove design. In a later stage torsional joints will be designed and suitable filler materials to realize leak proof joints will be evaluated.
\end{abstract}

Previous studies conducted by the Belgian Welding Institute (BWI) have shown promising results for the electromagnetic pulse welding process. As an alternative for the welding, magnetic pulse crimping can increase the applicability of the process, on the condition that the current shortcomings of the crimping process can be resolved (no clear guidelines for the groove design and the crimp joints are not gas-tight). The goal of the research is to make the magnetic pulse crimping a valuable, more robust and economically attractive alternative joining process.

\section{$1.1 \quad$ General principles}

Figure 1 schematically shows the layout of the magnetic pulse process. A capacitor bank is charged to the desired energy level by setting the correct voltage level using the machine's control unit. The energized capacitor bank is then discharged by flipping over a high current switch. This results in a damped oscillating current that flows through the coil, generating an intense transient magnetic field in it [2].

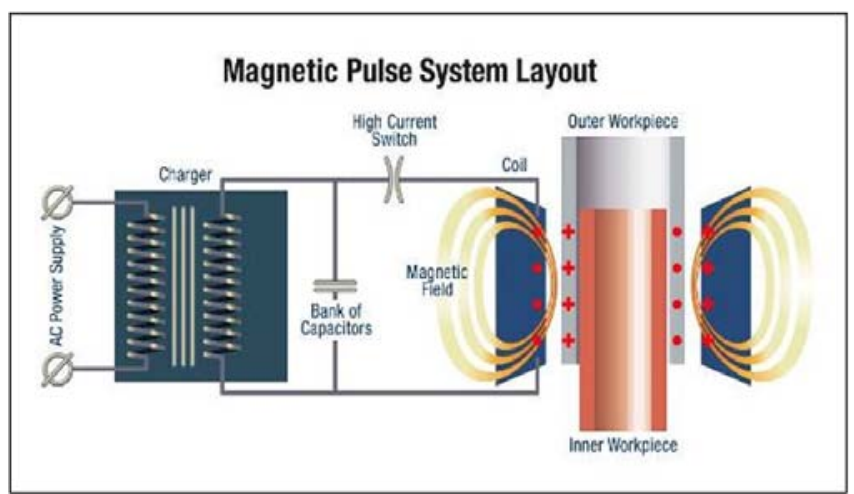

Figure 1: Schematic illustration of the magnetic pulse processs [3]

According to Lenz's law, eddy currents are induced in the surface layer of the outer workpiece (flyer tube). This is the so-called skin effect. The depth below the surface of the conductor at which the current density decays to a fraction $\frac{1}{6}$ of the current density at the surface is called the skin depth and can be calculated as [4]: 


$$
\delta=\sqrt{\frac{2 p}{\omega \mu}}
$$

With: $\quad \rho=$ resistivity of conductor $[\Omega m]$

$\omega=$ angular frequency of the current $[\mathrm{Hz}]$

$\mu=$ absolute magnetic permeability of the conductor $\left[\mathrm{Hm}^{-1}\right]$

As can be seen from the above equation, the skin depth varies with the inverse square root of the angular frequency of the current. Because the flyer tube is hollow, it is important that the frequency is high enough, so that the skin depth is smaller than its wall thickness. In that case the electromagnetic field is shielded by this flyer tube. If this is not the case, the induced magnetic field will be less effective and lead to limited deformation.

The eddy currents flow in such a direction that an induced magnetic field is created that initially shields the workpiece from the magnetic field inside the coil. During the proceeding of the process, the skin depth increases and the magnetic field penetrates the workpiece wall. The resulting pressure pulse acts orthogonally on the magnetic field inside the coil, and the Lorentz repulsion force causes the tube to repel away from the coil. When this force is greater than the workpiece material's yield strength, permanent plastic deformation occurs $[2,5]$.

The electromechanical forming process differs from conventional forming processes because it is environmental friendly, uses high strain rates and requires low maintenance. This new type of processing can be very interesting for several industries and therefore more applied research is required to obtain reliable data. The machine being used for the experiments is Pulsar's MPW 5025 Magnetic Pulse System. With an output voltage range of $0-19 \mathrm{kV}$ it is possible to perform experiments on difficult materials such as steel, which has a low electric conductivity compared to aluminium [6].

\subsection{Field shaper design}

Usually a multi-turn coil is used to induce the magnetic field. To protect this coil from high repulsion forces and to focus the widely spread current, a field shaper (FS) is used [7]. Field shapers can also homogenize and significantly increase the magnetic pressure in the work zone as can be seen in Figure 2. The tube experiences a bigger radial pressure at the ends because the coil length (in the case without field shaper) is larger than the axial field shaper length and the tube length. So all the energy left in the outer windings of the coil exerts a great pressure on the tube ends. When the axial length of the field shaper inner zone decreases, the magnetic pressure increases. This is illustrated on Figure 3 , which shows some experimentally obtained graphs where F1 is the field shaper with the smallest working area. This observation can be explained by assuming that magnetic field lines penetrating in a smaller area of the tube impose a stronger magnetic field (and thus higher pressure) in that area [8].

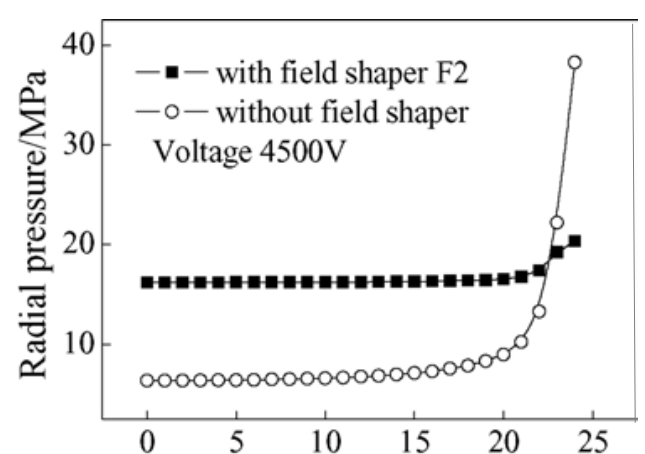

Distance from the center of tube $/ \mathrm{mm}$

Figure 2: Homogenization effect of FS [8]

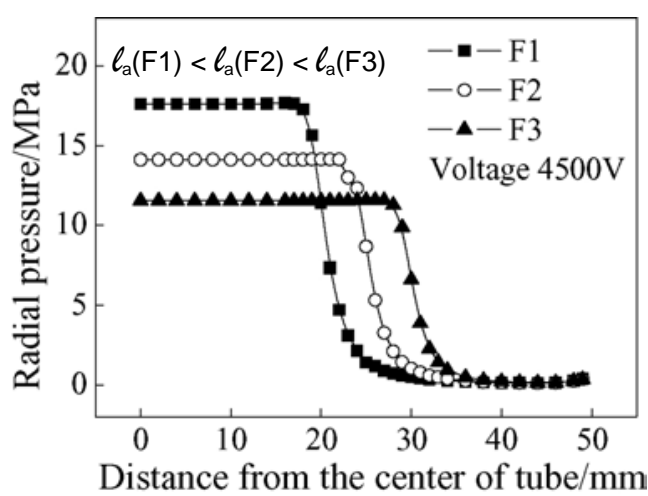

Figure 3: Increasing magnetic pressure effect of FS [8]

In the design of a field shaper, two main parameters need to be considered: its material and its geometry. As for the material, a good electrical conductivity and a high mechanical endurance against pulse loads and thermal shocks is required. As for the geometry, several contradictory demands need to be taken into account: the desired size and shape of the work zone, high stiffness, minimising mechanical and thermal stress (concentrations) and optimising energy coupling efficiency [7].

Optimising the efficiency is very important for reducing energy costs, which might be significant in case of bulk production. Unavoidable losses, like thermal and inductive losses, give rise to the potential problem of 
a low energy transfer efficiency. To investigate the efficiency of several shapes the finite element software FEMM (Finite Element Method Magnetics) can be used. A major drawback is the 2D characterization of the model, which can lead to inaccurate results [4].

Despite the inherent decrease in efficiency, the field shaper's geometrical design is chosen to suit the specific size and shape of the working zone. The field shaper stiffness is derived from electro-magnetic force considerations. By cutting a radial slit into the field shaper and decreasing the axial length of the field shaper, the current density increases resulting in a higher magnetic pressure in the work zone [9].

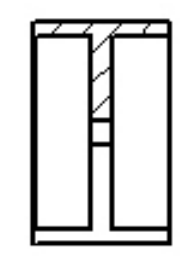

SECTION A-A

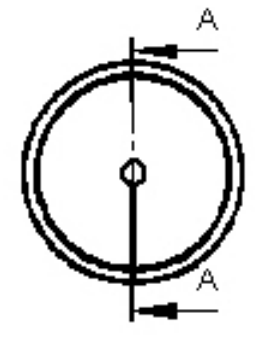

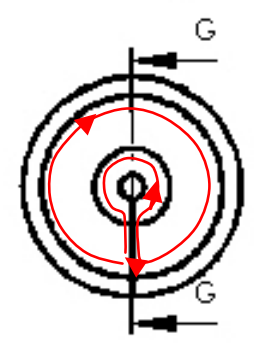

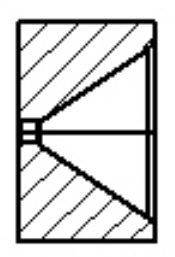

SECTION F-F

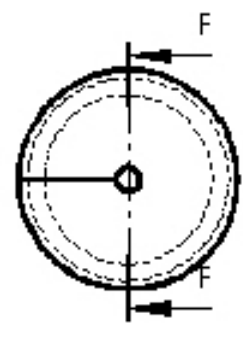

Figure 4: Three different geometrical designs of a field shaper

Figure 4 shows three possible geometrical designs of a field shaper. On the illustration of design $G$ a current line is drawn. It can be seen that due to the presence of a radial slit, the current flows in the high density area around the work zone. It has been proven that design A creates the highest coupling efficiency but provides the least mechanical strength and cracking will easily occur at the stress concentrations in the sharp corners. The efficiency of design $G$ only differs with $5 \%$ from that of design $A$ and has better mechanical strength. Design $G$ is the most widely used shape for a field shaper [7]. Design $F$ could be a good alternative because it combines a rectangular shape (less current losses and thus better coupling efficiency) with a conical shape (better mechanical performance). Because the magnetic pulse process deals with high pressures, the asymmetry of this last design will result in an asymmetrical distribution of stresses in the field shaper leading to reduced fatigue endurance.

Two field shapers have been developed according to design $G$ in Figure 4 to perform experimental research on the crimp joint. One field shaper is made of CuCrZr, has an inner diameter of $50 \mathrm{~mm}$ and an axial length of $30 \mathrm{~mm}$. The other field shaper is made of CuCoBe, has an inner diameter of $18 \mathrm{~mm}$ and an axial length of $20 \mathrm{~mm}$.

\section{JOINT DESIGN}

\subsection{Interference versus form fit}

For electromagnetic crimping, two mechanisms are of importance:

1. Interference fit: the flyer tube undergoes severe plastic deformation and the mandrel undergoes global elastic deformation. Once the crimping is done and the (electromagnetic) forces decrease, the mandrel wants to return to its original shape (elastic relaxation). This motion is restrained by the plastically deformed flyer tube. As a result, interference stresses are generated between both joining partners.

2. Form fit: the flyer tube is forced into an undercut (e.g. a groove), which is applied in the mandrel . The joint strength is thus the result of mechanical interlock.

\subsubsection{Interference fit}

The strength of the interference fit strongly depends on 3 factors: the residual stresses in the workpieces, the friction between both parts and the interaction area.

On the one hand, the residual stresses depend on strength and stiffness properties of both components. It is favourable to use a mandrel material of higher strength and stiffness than the tube material. Then the elastic recovery of the mandrel is higher, which leads to a higher radial reaction force and a higher pull-out strength of the joint [5].

On the other hand, the residual stresses also depend on the compression velocity. A higher velocity will lead to a higher kinetic energy at the time of impact and will realize a higher compression of the mandrel, which increases the radial reaction force and therefore realizes a higher pull-out strength. A higher compression velocity can be reached by setting a higher charging voltage or by having an initial gap between both joining partners (because then there is the possibility for acceleration, but it should be noted 
that the initial gap cannot be too large, because then the acceleration will have switched to deceleration by the time the flyer tube impacts on the mandrel ) [10].

The second factor that is of importance is the static friction coefficient between the materials of the outer tube and the mandrel. In Table 1 the values are giving for combinations which will be investigated in this thesis.

\begin{tabular}{c|c} 
Joined materials & $\mu_{\Omega}$ \\
\hline steel-steel & 0.74 \\
\hline aluminum-steel & 0.61
\end{tabular}

Table 1: Static friction coefficients for the investigated material combinations [11]

The third important factor is the interaction area, which depends on the roughness of the parts and the size of the contact zone.

An increasing roughness of the surfaces will lead to a microscopic form fit and a higher percentage of interaction area in the joints and consequently higher pull-out strengths [5].

A larger contact area will lead to stronger joints (assuming that the other factors remain constant). For tubular joints, the diameter of the mandrel and the length of the contact zone are the two parameters which determine the size of the contact area. The diameter of the mandrel is in most cases a fixed parameter determined by the application, but the length of the contact zone (the overlap length) is a parameter which can be varied when designing connections. A large length is desirable, but of course a good balance needs to be found between increasing the length (leading to a higher pull-out strength) and the inherent higher cost (more material, larger machine, more energy) [2].

It should also be noted that an interference fit developed by impact eliminates the potential for fretting (this is wear due to microscopic movements in the interference fit during its operation) [12].

\subsubsection{Form fits}

To determine the optimal shape of the groove, three options have been evaluated: triangular, circular and rectangular grooves. Joints with triangular grooves were always found to be the weakest. The explanation is that for triangular grooves the angle $\alpha$ (see the radioscopic pictures after deformation in Figure 5) is greater than for rectangular or circular grooves. This results in a lower degree of tube deformation at the groove edge, and thus a lower tensile force is required to initiate pull-out of the tube material from the groove. The circular grooves have a smaller resulting angle $\alpha$ than the rectangular ones, but these last still have a larger pull-out strength because of the larger amount of shearing of the tube. This locks the tube better in place, and thus higher joint strength can be expected. This has been experimentally verified in [1].
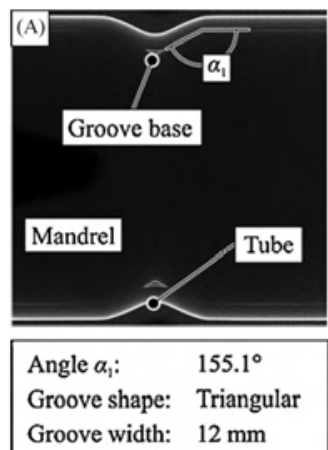

Groove width: $12 \mathrm{~mm}$

Groove depth: $3 \mathrm{~mm}$

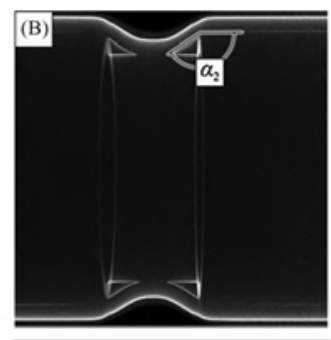

Angle $\alpha_{2}: \quad 145.2^{\circ}$ Groove shape: Rectangular Groove width: $12 \mathrm{~mm}$ Groove depth: $3 \mathrm{~mm}$

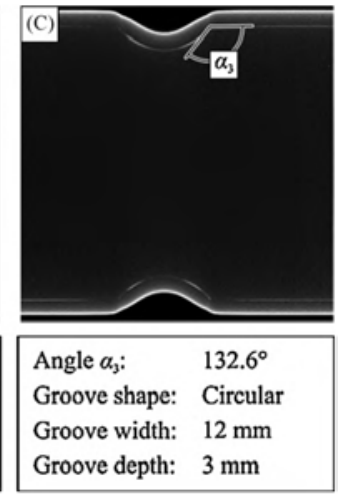

Groove depth: $3 \mathrm{~mm}$

Figure 5: Triangular, rectangular and circular grooves [1]

The performance of the rectangular groove strongly depends on 3 factors: the groove depth, the groove width and the groove radii (Figure 6).

Deeper grooves will lead to higher joint strengths [14-15], but a too deep groove will lead to a decrease in strength as a result of shearing at the groove edges [16].

For the groove width, it was first believed that a narrow groove would lead to high joint strengths [14-15]. This was later revised because an increasing width leads to a larger contact area at the base of the groove. A larger interference fit and a stronger joint strength will thus be obtained. Again, there is a limit to the dimension, because a too wide groove will lead to wrinkling of the tube which clearly has a negative effect 
on joint strength [16]. Furthermore an economical factor comes into play, because a larger width requires more overlap (more material) and a higher energy.

A smaller edge radius at the top of the groove leads to a higher joint strength, but a too small radius leads to increased shearing at the edge and negatively affects the joint strength [16].

Additional grooves in the joining zone will significantly increase the strength of a form fit connection[1]. To verify this statement, a few experiments were performed in a preceding thesis. Joints were produced using mandrels with two grooves and evaluated by tensile testing [13].

The above discussions clearly illustrate the need for more and in-depth theoretical and experimental research activities with respect to the design of mandrel grooves for optimal joint performance.

\subsection{Finite element analysis}

Finite element simulations of a tensile loaded joint have been performed using the software ABAQUS. The main goal is to get confirmation that a second groove will increase the load bearing capacity of an axially loaded joint. Hereto the magnitude and distribution of the stresses and deformations in both components are studied in detail.

An axisymmetric model consisting of a steel mandrel with two grooves (with a groove width and depth of respectively $13 \mathrm{~mm}$ and $2 \mathrm{~mm}$, separated $10 \mathrm{~mm}$ apart) and an aluminium tube (with a wall thickness of 1,5 $\mathrm{mm}$ and with its assumed deformed shape obtained after crimping) was built. Linear elastic material behaviour is assumed. The static friction coefficient between steel and aluminium (see Table 1) was used to define the interaction between both parts. The mandrel was clamped at the bottom and an upwards displacement was imposed at the tube end. The resulting stress distribution in the axial direction obtained for a representative simulation can be seen in Figure 7. In the unloaded condition, the aluminium tube makes contact with the mandrel at the bottom of both grooves.
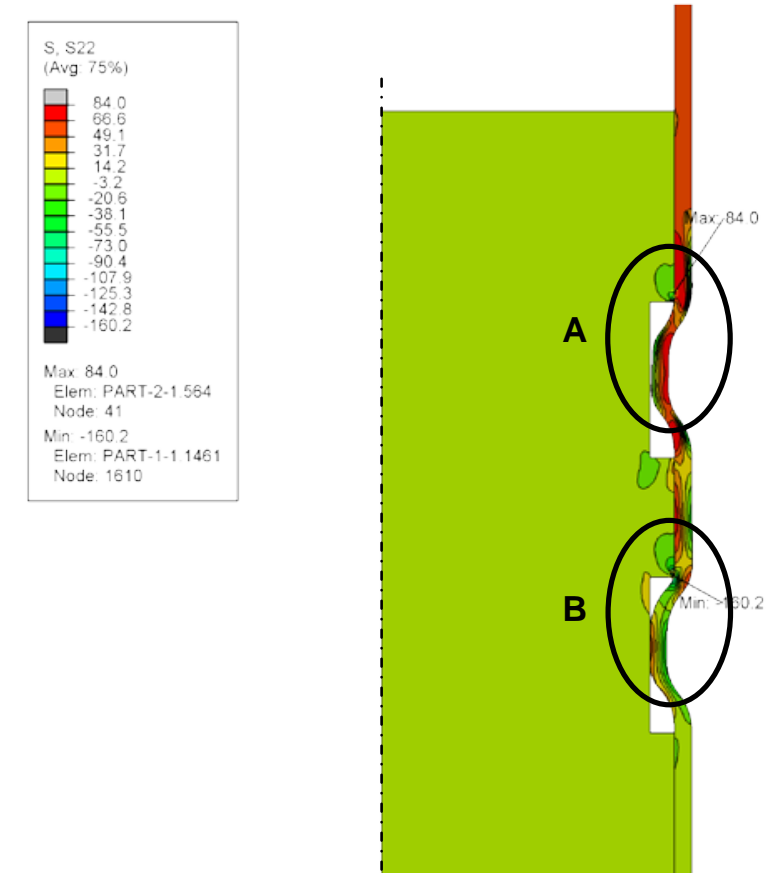

detail A

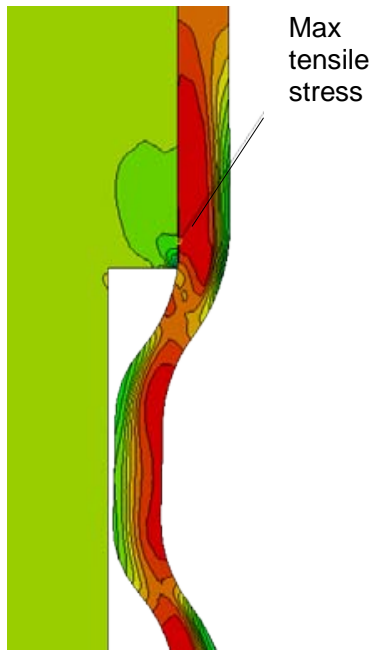

$\underline{\text { detail B }}$

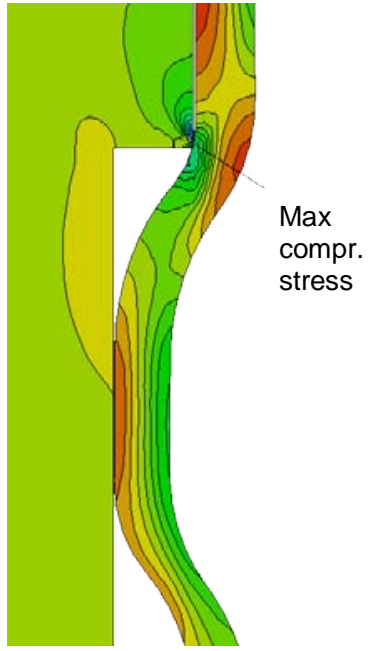

Figure 7: Stress distribution in a tensile loaded joint with a double grooved mandrel

The simulation results revealed that a clearance appeared at the bottom of the first groove during the tensile loading (Figure 7A). As a consequence, the tube is pulled out of the first groove and the mechanical interlock behind the upper corner of the second groove becomes the most important mechanism that prevents the tube from sliding off the mandrel. The highest compression stress in the mandrel can therefore be found at this corner (Figure 7B). The highest tensile stress is found in the tube near the upper corner of the first groove (Figure 7A).

Based on these conclusions, the joint design can be further optimized. The edge radius of the upper corner of the first groove is made larger and this groove is made less deep, in order to prevent early localized shearing of the tube. Also, the first groove is made wider to obtain a larger contact area at the base of the first groove, thus creating a stronger interference fit that will longer withstand pull-out. The second groove is deeper than the first groove and the edge radius of the upper corner is made larger to optimize the form fit 
and joint strength. In order to verify these conclusions through experiments, tensile tests were done on both a mandrel with two equal grooves and a mandrel with the proposed optimized grooves, and the results were compared (see section 2.3). More finite element simulations to optimize the groove design will be done in the future.

\subsection{Experimental research}

\subsubsection{Double grooved mandrel}

To verify the finite element results, two different types of steel mandrels (with an outer diameter of 46,8 $\mathrm{mm}$ ) were made: one with two equal grooves and one with optimized grooves that were proposed in section 2.5 (Figure 8a and Figure 9a). An aluminium tube with an outer diameter of $50 \mathrm{~mm}$ and a wall thickness of $1,5 \mathrm{~mm}$ was crimped on the mandrels. Experimentally it was determined that a charging voltage of $12,6 \mathrm{kV}$ resulted in a good deformation of the tube into the grooves, as can be seen on longitudinal cross sections (Figure $8 b$ and Figure 9b). It should be noted that the radial clearance between the tube and the mandrel is due to the elastic recovery (removal of the residual stresses) when the joints are cut through.

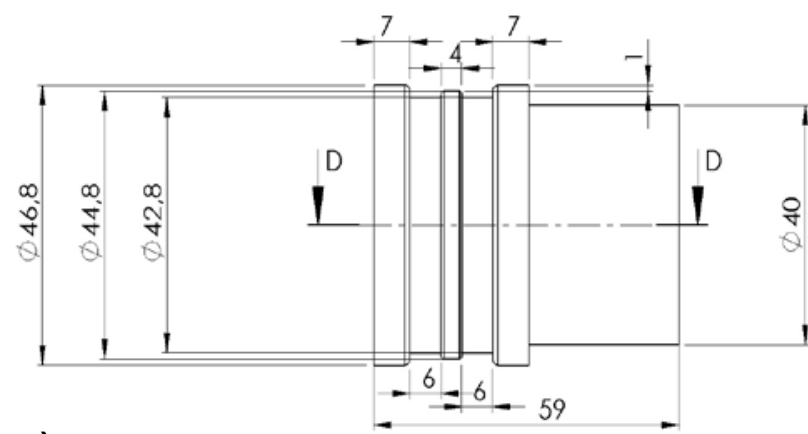

a)

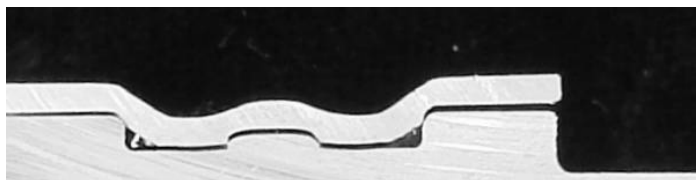

b)

Figure 8: Mandrel with two equal grooves

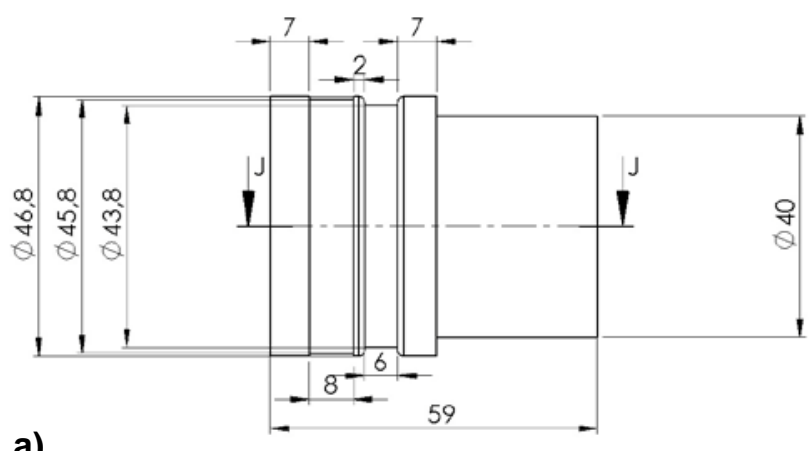

a)

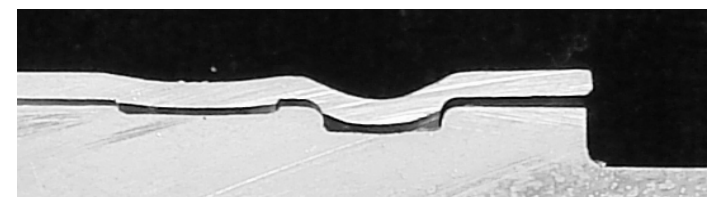

b)

Figure 9: Mandrel with optmized grooves

Tensile tests were done on tubular base material and on the crimped joints. The base material had a tensile strength of 56,1 kN. The joint design with two equal grooves had a pull-out strength of $45,4 \mathrm{kN}$, whereas the joint design with optimized grooves had a much higher pull-out strength of $53,8 \mathrm{kN}$. All tested joints failed at the position where the finite element simulation predicted the highest tensile stresses in the tube (Figure 10).

The results from the finite element simulations were confirmed, but further optimization of the grooves is necessary in order to get the pull-out strength closer to the strength of the base material. An optimal joint would be stronger than the base material.

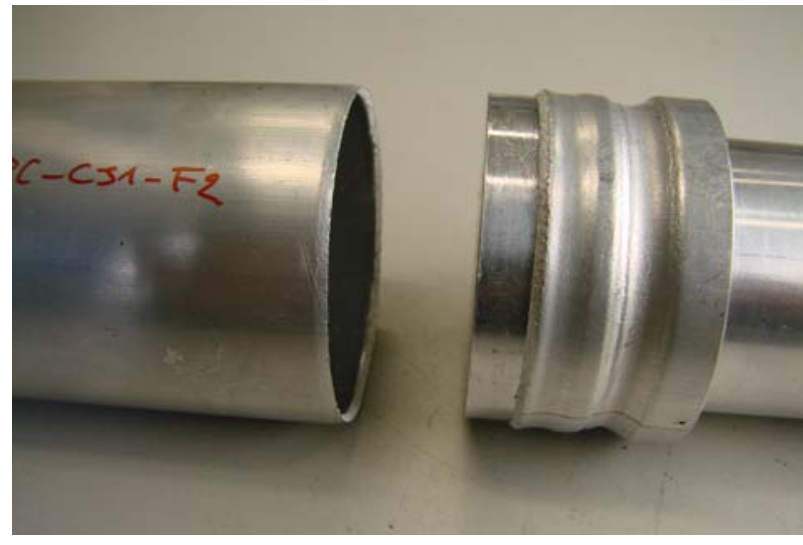

Figure 10: Specimen after tensile test: joint failure occurs due to shearing at the upper edge of the first groove

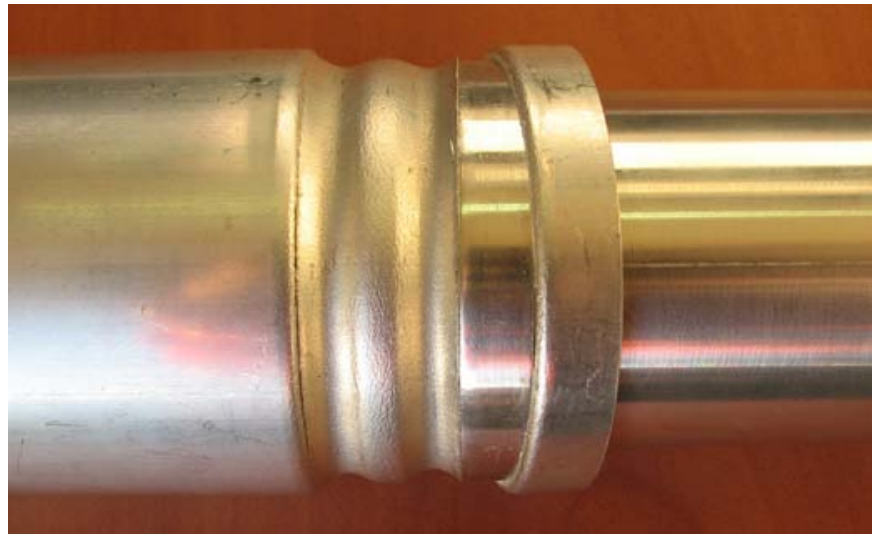

Figure 11: Mandrel with sharp edges cuts the tube 
More experiments were done to investigate the influence of the groove radii. As expected it can be concluded that sharp edges combined with deep grooves should not be used in the joint design, because the mandrel then acts as a cutting tool (Figure 11).

Table 2 shows the parameters used for all the experiments. Groove 1 is the groove near the mandrel's end, which is to be chosen long and shallow. The shallower the groove, the smaller the edge radius can be without cutting the tube. Specimen $\mathrm{H}$ has the highest tensile strength, but the grooves still need further optimization to create a joint which is stronger than the base material.

\begin{tabular}{|c|c|c|c|c|c|c|c|c|c|c|c|}
\hline $\begin{array}{c}\text { sample } \\
\text { name }\end{array}$ & \multicolumn{4}{|c|}{ groove 1 } & \multicolumn{2}{c|}{ middle } & \multicolumn{4}{c|}{ groove 2 } & $\begin{array}{c}\text { tensile } \\
\text { strength } \\
{[\mathbf{k N}]}\end{array}$ \\
\hline & radius & width & depth & radius & width & depth & radius & width & depth & radius & A \\
\hline & 1 & 6 & 3,5 & 1 & 4 & 1 & 1 & 6 & 3,5 & 1 & 39,94 \\
\hline B & 0 & 6 & 3,5 & 0 & 4 & 1 & 0 & 6 & 3,5 & 0 & 23,25 \\
\hline C & 1 & 6 & 2 & 1 & 4 & 0 & 1 & 6 & 3 & 1 & 39,26 \\
\hline D & 1 & 8 & 1,5 & 1 & 4 & 0 & 1 & 4 & 2,5 & 1 & 41,66 \\
\hline E & 1 & 6 & 2 & 0,5 & 4 & 1 & 0,5 & 6 & 2 & 1 & 45,41 \\
\hline F & 0 & 6 & 2 & 0 & 4 & 1 & 0 & 6 & 2 & 0 & 47,98 \\
\hline G & 0,5 & 6 & 1 & 0 & 4 & 0,5 & 1 & 6 & 2 & 1 & 37,89 \\
\hline H & 0 & 8 & 0,5 & 0 & 2 & 0 & 1 & 6 & 1,5 & 1 & 53,83 \\
\hline
\end{tabular}

Table 2: Results of the experiments with different configurations for the double groove mandrel

\subsubsection{Industrial case study based on a single groove}

The industrial case study is a steel to steel joint based on a single groove design. Both pieces are made of the same carbon steel and their dimensions are shown in Figure 12. Crimping experiments are performed to gain more insight in magnetic pulse forming of steel and on the effect of changing overlap lengths. The joint performance and quality will be evaluated by means of tensile tests and macroscopic examination of cross sections. A field shaper with inner diameter of $18 \mathrm{~mm}$ and axial length of $20 \mathrm{~mm}$ is used. Figure 12 clarifies the set up and indicates the three parameters that will be varied during the experiment: overlap length of field shaper and tube, overlap length of tube and mandrel, and the length of the rod end.

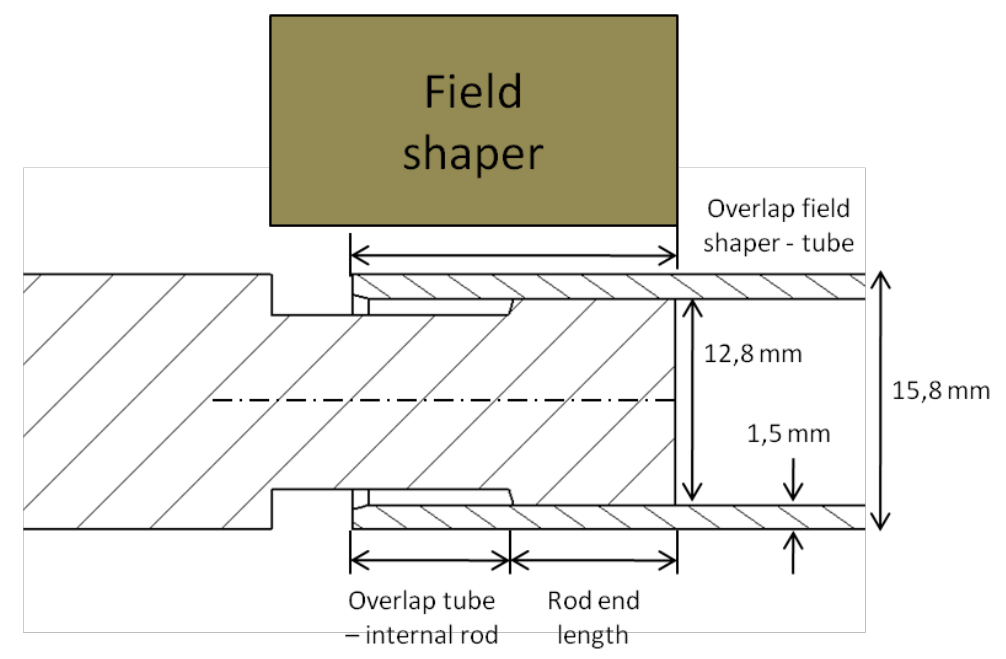

Figure 12: Industrial case study: axially loaded steel to steel crimp joint

For the first test series, the charging voltage of the machine was set to $10 \mathrm{kV}$. Visual inspection revealed that there was hardly any deformation, so the charging voltage was increased to $15 \mathrm{kV}$. Now the flyer tube was deformed but there was still a clearance between the mandrel's groove bottom and the deformed tube. Following, the maximum charging voltage $(19 \mathrm{kV})$ was used to obtain a satisfactory result. Additional experiments at three distinct charging voltages between $15 \mathrm{kV}$ and $19 \mathrm{kV}$ were performed. Table 3 gives an overview of all performed experiments and the corresponding parameters. Every combination of process parameters is tested at least twice. The table also lists the evaluation methods and the available results of tensile tests. Eccentricity will be measured for several crimped joints:. the specimen will be clamped on a lathe and during rotating a dial test indicator will measure errors on the eccentricity. 


\begin{tabular}{|c|c|c|c|c|c|c|}
\hline Series & $\begin{array}{c}\text { Charging } \\
\text { voltage } \\
{[\mathrm{kV}]}\end{array}$ & \begin{tabular}{|c|}
$\begin{array}{c}\text { Overlap } \\
\text { field } \\
\text { shaper - } \\
\text { tube [mm] }\end{array}$ \\
\end{tabular} & $\begin{array}{c}\text { Rod end } \\
\text { length } \\
{[\mathrm{mm}]}\end{array}$ & $\begin{array}{l}\text { Overlap } \\
\text { tube - } \\
\text { internal } \\
\text { rod [mm] }\end{array}$ & Investigation method & $\begin{array}{c}\text { Axial } \\
\text { tensile } \\
\text { load [kN] }\end{array}$ \\
\hline \multirow{7}{*}{1} & 15 & 15 & 10 & 10 & Eccentricity + tensile test & \\
\hline & 16 & 15 & 10 & 10 & Eccentricity + tensile test & \\
\hline & 17 & 15 & 10 & 10 & Eccentricity + tensile test & \\
\hline & 18 & 15 & 10 & 10 & Eccentricity + tensile test & \\
\hline & 19 & 15 & 10 & 10 & Eccentricity + tensile test & \\
\hline & 19 & 15 & 10 & 10 & Tensile test & 30,7 \\
\hline & 19 & 10 & 10 & 10 & Tensile test & 33,3 \\
\hline \multirow{3}{*}{2} & 19 & 10 & 10 & 5 & Eccentricity + cross section & \\
\hline & 19 & 10 & 10 & 5 & Eccentricity + tensile test & \\
\hline & 19 & 10 & 10 & 5 & Eccentricity + tensile test & \\
\hline \multirow{3}{*}{3} & 19 & 8 & 10 & 3 & Eccentricity + cross section & \\
\hline & 19 & 8 & 10 & 3 & Eccentricity + tensile test & \\
\hline & 19 & 8 & 10 & 3 & Eccentricity + tensile test & \\
\hline \multirow{3}{*}{4} & 19 & 8,5 & 5 & 5 & Cross section & \\
\hline & 19 & 8,5 & 5 & 5 & Tensile test & 25,8 \\
\hline & 19 & 8,5 & 5 & 5 & Tensile test & \\
\hline
\end{tabular}

Table 3: Overview of test parameters and evaluation methods used for the industrial case study

Most of the evaluations are still in process, so it is not yet possible to formulate clear conclusions.. However, the tensile test results obtained so far are promising. Reducing the overlap length of the field shaper and the tube, increased the strength of the joint from $30,7 \mathrm{kN}$ to $33,3 \mathrm{kN}$. This can be explained by noticing that reducing the working area, results in a stronger magnetic pressure (as already discussed in paragraph 2.2) and increasing joint strength.

Figure 13 shows a cross section of a specimen from the fourth series, where localized thinning and shearing can be clearly seen at the edge of the mandrel. However, during the tensile test on that sample, the tube slid off the mandrel instead of breaking (which was the case for the other samples, Figure 15). Figure 14 shows the four visible cracks in the tube, each under an angle of 90 degrees. This is a natural consequence of the radial pressure working on the tube during its sliding.

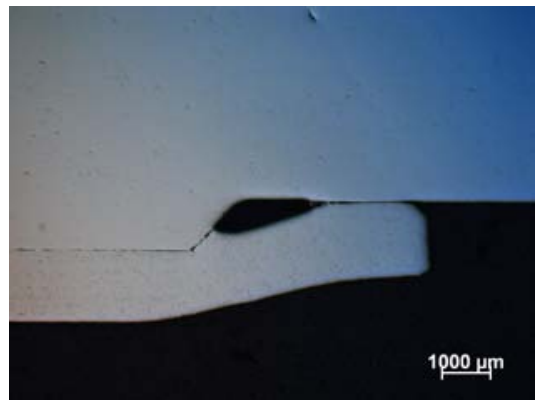

Figure 13: Cross section illustrating localized thinning and shearing of the tube

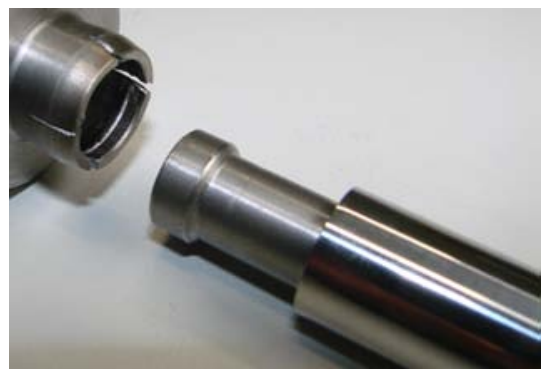

Figure 14: Tube with 4 cracks as a result of radial forces during relative sliding in the tensile test

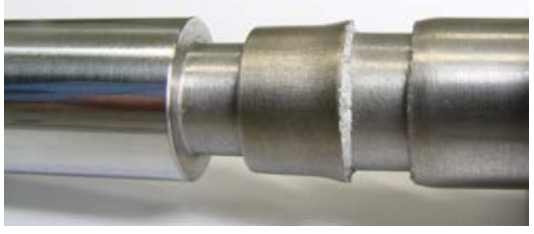

Figure 15: Shearing of tube metal during tensile test

From literature, it was concluded that a rectangular shaped groove results in a strong axial joint. Adding a second groove may have a positive influence on the joint strength. Finite element analyse shows a clear contribution of a second groove. Based on the simulations an optimal design is proposed and tested.

The experiments on a double grooved mandrel confirmed the assumption that an optimized groove design consists of a first groove which is less deep and wider than the second groove. The tensile strength of the designed crimp joint is however still lower than the tensile strength of the base material. Thus further optimization of the grooves' dimensions is needed. Experiments also showed that if the groove radius is too small compared to its depth, the mandrel's edge will cut the tube. Further optimization of the double groove design will be done based on a combination of simulations and experiments. 
The industrial case study of a steel to steel joint showed that for this material combination, a large voltage is needed in order to get a good joint. A joint strength higher than the base material was accomplished. Macroscopic images showed that a too sharp edge of the mandrel causes localized shearing and thinning of the tube. If the groove depth is small, the tube rather slips than shears at the edge, causing a weaker joint strength. In case of slipping, failure occurs by cracking of the tubular part More tensile tests and eccentricity measurements still need to be performed.

Based on the obtained results and a more experiment trials, process windows will be developed. A process window is a tool that can be used by an operator to easily determine the minimal charging voltage that is needed to obtain a sound joint for a given groove design.

By using axial groove cuts in the surface of the mandrel, a torque crimp joint can be designed. The influence of the axial groove parameters will be evaluated using the same approach as for the tension loaded crimp joints.

The suitability of different filler materials (rubber and solder) to be used in the magnetic pulse process and realize gas-tight crimp joints will be experimentally evaluated. Rubber sealing rings can be compressed easily and are widely used for various applications. Solder metals deform easily and can therefore fill the open areas without using too much energy.
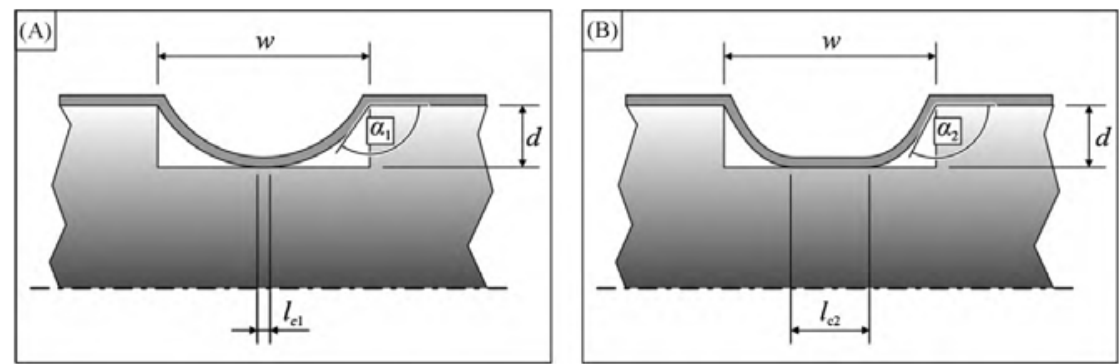

Figure 16: (A) connection with minimal needed voltage, (B) connection with a larger voltage than is minimally needed [1]

ACKNOWLEDGEMENTS

The present work was partially performed within the framework of the Cornett project "PULSCRIMP". Support from the Flanders region (IWT - Agency for Innovation by Science and Technology) is gratefully acknowledged. The authors also would like to acknowledge the support of Oleg Zaitov (BWI) for his help during the evaluation of the experiments and Matthias Verstraete (UGent) for his help with ABAQUS.

5

\section{REFERENCES}

Weddeling, C., Woodward,S.,Marré,M.,Nellesen,J.,Psyk,V.,Tekkaya,E.,Tillmann,W., Influence of groove characteristics on strength of form-fit joints. Journal of Materials Processing Technology, 2010.

Dehra, M.S., High velocity formability and factors affecting it, in Materials Science and Engineering. 2006, Ohio State University. p. 336.

Innovative electromagnetic high-velocity welding techniques. 2008; Available from: http://www.bilibs.be/NL/Onderzoek/Beelden/MPWeld.jpg.

Bahmani, M.A., K. Niayesh, and A. Karimi, 3D Simulation of magnetic field distribution in electromagnetic forming systems with field-shaper. Journal of Materials Processing Technology, 2009. 209(5): p. 2295-2301.

5] Hammers, T., et al., Influence of Mandrel's Surface and Material on the Mechanical Properties of Joints Produced by Electromagnetic Compression. Steel Research International, 2009. 80(5): p. 366-375.

Pulsar, Manual MPW 5025 Magnetic Pulse System.

in The review of scientific instruments. 1965: Berkshire, England. Haiping, Y., et al., Effect of field shaper on magnetic pressure in electromagnetic forming. Journal of Materials Processing Technology, 2005. 168(2): p. 245-249.

Pulsar (2008) Coil/field shaper designing (company guidelines).

Schulze, V., Barreiro, P., Löhe,D., Investigation of the Influence of Process Parameters on the Structure and the Mechanical Properties of Joints Produced by Electromagnetic Compression. Advanced Materials Research, 2006. 10: p. 79-88. 
[11] Friction coefficients. Available from: http://www.engineershandbook.com/Tables/frictioncoefficients.htm.

[12] Eguia, I., Zhang, P., Daehn G.S., Improved crimp joining of aluminium tubes onto mandrels with undulating surfaces, in Proceedings of the 1st International Conference on High Speed Forming. March 31 -April 1 2004: Dortmund, Germany. p. Pages 161 - 170.

[13] Broekaert, F., De Ketele,M., An exploratory study into the feasibility of magnetic pulse forming, in Mechanical construction and production. 2009, Gent. p. 284.

[14] Bühler, H., von Finckenstein, E., Fügen durch Magnetumformung. Werkstatt und Betrieb 101, 1968: p. 671-675.

[15] Golavashchenko, S. Methodology of design of pulsed electromagnetic joining of tubes. in Proceedings of the TMS Symposium "Innovations in Processing and Manufacturing of Sheet Materials". 2001. New Orleans,LA,USA.

[16] Park, Y., Kim, H. , Oh, S., Design of axial/torque joints made by electromagnetic forming. Thinwalled structures 43, 2005: p. 826-844. 